\title{
Biomedical agency floats open-access plan
}

\section{Geoff Brumfiel, Washington}

The main biomedical research agency in the United States has issued a plan that would make the results of all research that it supports freely available shortly after their initial publication in the scientific literature.

On 3 September, the National Institutes of Health (NIH) posted the plan on its website. It would require all grantees to place their final versions of accepted manuscripts - or the published version itself if the publisher agrees - on the US National Library of Medicine's PubMed Central database within six months of publication.

Comments are invited within 60 days on the plan, which broadly complies with some advisory language that was added to the NIH's budget bill by a congressional committee in July. The NIH is expected to decide on the version to be implemented shortly after that. Details of the plan's implementation will be closely scrutinized by scientific publishers.

"We are aware of many of the implications of possible changes," NIH director Elias Zerhouni told a meeting of representatives of scientific societies and patient advocacy groups at the agency's main campus in Bethesda, Maryland, on 31 August. "At the same time, the mission of the NIH includes delivering research information to the public."

The plan acknowledges, however, that this mission must be "balanced with the ability of journals and publishers to preserve their critical role in the peer review, editing and scientific quality control process".

But some publishers oppose the plan, complaining that they have not been sufficiently consulted on its impact on the established scientific communication system. "This is being done rather stealthily," complains Allan Adler, head of government affairs at the Association of American Publishers in Washington DC. “There's been no real discussion of what this is going to cost the taxpayer, or of its impact on publishers."

"Zerhouni is making us all do this experiment," says Martin Frank, executive director of the American Physiological Society in Bethesda, Maryland. "The federal government is trying to regulate the dissemination of information at the expense of an established, diverse publishing operation."

Advocates of open access strongly support the proposed policy change. "I applaud what he's doing," says Harold Varmus, former director of the NIH and president of the Memorial Sloan-Kettering Cancer Center in New York City. "To hide NIH research behind high subscription fees is not fair," he says.

Varmus says that the six-month delay will allow publishers to continue generating income from subscriptions. But Samuel Kaplan, a microbiologist at the University of Texas Medical School in Houston and chair of the publishing board of the American Society for Microbiology, says that won't be the case, particularly for smaller journals that publish quarterly. "It could be the death-knell of society publications," he predicts.

If implemented in its current form, the NIH plan will be an important victory for advocates of open access to the scientific literature. In July, the House of Commons Science and Technology Committee advised the UK government to encourage universities there to make all their papers freely available online (see Nature 430, 390; 2004).

Richard Roberts, a geneticist at New England Biolabs in Beverly, Massachusetts, says that open access is rapidly gathering momentum. On 26 August, Roberts, Varmus and 23 other Nobel laureates co-signed a letter calling on Congress and the NIH to provide open access to government-funded research.

But Frank pledges that the scientific societies will do what they can to amend the NIH's proposal. "We won't roll over," he says. "We will continue to fight this."

http://grants1.nih.gov/grants

\section{Ocean fix for climate change finds tentative support}

\section{Jim Giles}

Marine organisms can sense and avoid high concentrations of carbon dioxide, according to a study of a seafloor vent off the coast of Hawaii. The result provides tentative support for plans to tackle climate change by dumping carbon dioxide in the ocean.

Researchers have long been concerned that adding high concentrations of $\mathrm{CO}_{2}$ to the ocean might cause serious damage to local marine life - some studies have shown that it can kill marine organisms such as nematodes (see Nature 430, 391; 2004). Environmentalists have blocked some plans to conduct further tests, fearing that even small injections of $\mathrm{CO}_{2}$ might open the door to larger tests or industrial projects.

So the researchers turned instead to studying a natural plume of $\mathrm{CO}_{2}$ that bubbles up from a subsea volcano called Loihi, near Hawaii. They wanted to assess fears that adding $\mathrm{CO}_{2}$ to the ocean might create a 'mortality sink' - a spot where marine organisms die, attracting scavenging creatures that would in turn be killed.

But this kind of death trap is unlikely to occur, says Jeffrey Summers, a physicist with the Office of Fossil Energy at the US energy department in Washington DC. Summers and colleagues set cages baited with mackerel close to the Loihi plume and at various distances from the $\mathrm{CO}_{2}$. The bait away from the plume was eaten in less than 24 hours, whereas the bait over the vent remained untouched for more than a week.

Eric Vetter, a marine biologist at Hawaii Pacific University who worked with Summers on the project, thinks animals are avoiding the cages because they can sense the high $\mathrm{CO}_{2}$ levels. "The results are promising," he says.

The study, scheduled to be presented on 6 September at the 7th International Conference on Greenhouse Gas Control Technologies in Vancouver, Canada, also suggests that sea creatures can recover from short blasts of $\mathrm{CO}_{2}$. Summers' team dragged cages of amphipods - shrimp-like creatures - over the vent. The animals seemed to be anaesthetized by the gas within 10 minutes, but became active again around half an hour after being removed from the plume.

Vetter stresses that the work is "very preliminary", and adds that much more data are needed before conclusions can be drawn about the wisdom of dumping $\mathrm{CO}_{2}$ in the sea. 